\title{
Treatment of Young Rats with Cholestyramine or a Hypercholesterolemic Diet does Not Influence the Response of Serum Cholesterol to Dietary Cholesterol in Later Life
}

\author{
A.C. Beynen ${ }^{1,2, *}$, J.J. De Bruijne ${ }^{3}$ and M.B. Katan ${ }^{2}$ \\ ${ }^{1}$ Department of Laboratory Animal Science, State University, P.O. Box 80.166, 3508 TD Utrecht; \\ 2 Department of Human Nutrition, Agricultural University, De Dreijen 12, 6703 BC Wageningen; and \\ ${ }^{3}$ Small Animal Clinic, State University, P.O. Box 80.154, 3508 TD Utrecht (The Netherlands)
}

(Received 19 November, 1984)

(Revised, received 18 June, 1985)

(Accepted 18 June, 1985)

\section{Summary}

Groups of 10 female Wistar rats (aged 4 weeks) were fed for 29 days either a low-cholesterol commercial diet, a commercial diet containing $2 \%(\mathrm{w} / \mathrm{w})$ cholesterol, $0.5 \%$ cholate and $5 \%$ olive oil or a diet containing $2 \%$ cholestyramine. The rats were then fed the low-cholesterol commercial diet for the next 91 days and the highcholesterol diet for another 29 days. There was no significant difference between the groups in the increase of cholesterol in serum and liver during the last period of cholesterol feeding. A fourth group of 10 animals was fed the diet containing cholesterol and cholate during the entire experimental period of 149 days. By the end of the experiment serum cholesterol in these animals was lower and liver cholesterol was higher than in the 3 groups fed the high-cholesterol diet during days 120-149 of the experiment. This study does not present evidence for imprinting effects of early diet manipulation on the later cholesterolemic response to a high cholesterol diet.

This study was supported by the Netherlands Heart Foundation, Grant No. 31.013, and an established investigatorship to M.B.K.

* Author to whom correspondence should be addressed at the Department of Laboratory Animal Science.

Abbreviations: low = low-cholesterol diet; high = high-cholesterol diet; cholestyramine $=$ diet containing cholestyramine. 
Key words: Dietary cholesterol - Dietary cholestyramine -Liver cholesterol - Liver function-Long-term effects -Plasma cholesterol

\section{Introduction}

The pediatric age has been frequently implicated in the early onset of atherosclerosis [1,2]. The question may then arise whether in humans the composition of the early diet affects the subsequent serum cholesterol concentration, which is an important risk factor for the development of atherosclerosis. Studies that addressed this question have not led to conclusive results. In some studies various milks and formulas fed during the 1st year of life did affect later serum cholesterol levels $[3,4]$, but this was not found in other studies $[5,6]$.

The conflicting results in humans may be due to lack of control of various factors that influence cholesterol metabolism. Animal studies are therefore indicated to provide more information as to possible imprinting effects on cholesterol metabolism. Feeding of the serum cholesterol lowering bile acid binding resin, cholestyramine, for 4-6 weeks significantly lowered the response of serum cholesterol to dietary cholesterol measured 4 to 6 weeks later in neonatal [7] and post-weaned [8] guinea pigs. No such data are available for rats. It has been suggested $[9,10]$ that high, early cholesterol intakes by rats reduced the serum cholesterol response to cholesterol feeding in later life, but other workers did not provide evidence for such an effect (11-13). The present study was undertaken to see whether in rats early feeding of a diet containing cholestyramine or cholesterol and cholate affects the later response to the intake of cholesterol plus cholate. The response was measured as the concentration of cholesterol in serum as well as in liver.

\section{Materials and Methods}

\section{Animals, diets and experimental design}

We used female rats because they are more sensitive to the hypercholesterolemic diet than males [14]. The rats, aged 4 weeks, were from our random-bred Wistar colony (Small Animal Center, CKP, Agricultural University), and are descendants of the Wistar CPB/WU strain, purchased about 3 years ago from the Central Institute for the Breeding of Laboratory Animals, CPB-TNO, Zeist, The Netherlands. Until day 0 of the experiment the animals were fed a commercial, pelletted rat diet (RMH-B ${ }^{\circledR}$, Hope Farms, Woerden, The Netherlands). According to chemical analysis (Weende method) the composition of the commercial diet was as follows $(\mathrm{g} / 100$ g): moisture, 12.5; ash, 4.8; crude protein, 24.1; crude fat, 5.9, and crude fiber, 4.1. The animals were kept in groups of 5 animals in cages $(120 \times 42 \times 19 \mathrm{~cm})$ constructed of stainless steel with wire mesh bases. They were housed in a room with air conditioning $\left(20^{\circ} \mathrm{C}\right)$, controlled lighting (light: $06.00-18.00 \mathrm{~h}$; dark: $18.00-06.00 \mathrm{~h}$ ) and humidity $(55-65 \%)$.

At day 0 of the experiment, the rats were divided into 5 groups, each consisting of 
TABLE 1

EXPERIMENTAL DESIGN

\begin{tabular}{llllll}
\hline & \multicolumn{4}{l}{ Dietary group code } & \\
\cline { 2 - 6 } & A & B & C & D & E \\
\hline Days $0-28$ & low & high & low & high & cholestyramine \\
Days $29-119$ & low & high & low & low & low \\
Days $120-149$ & low & high & high & high & high \\
\hline
\end{tabular}

Abbreviations: low $=$ low-cholesterol diet; high $=$ high-cholesterol diet; cholestyramine $=$ diet containing cholestyramine.

10 animals. The groups had similar distributions of serum cholesterol concentration, body weight and litter origin. Group A received the low-cholesterol, commercial diet (analysed cholesterol content, $23 \mathrm{mg} / 100 \mathrm{~g}$ ) for 149 days. Group B received the high-cholesterol diet for 149 days. The high-cholesterol diet consisted of the commercial diet $(92.5 \%, \mathrm{w} / \mathrm{w})$ to which $2 \%$ cholesterol (Duphar BV, Veenendaal, The Netherlands), 0.5\% sodium cholate (Sigma Chemical Co., St. Louis, MO, U.S.A.) and $5 \%$ olive oil (Levant ${ }^{\otimes}$, Huilerie L'Abeille, Marseille, France) had been added. Group $\mathrm{C}$ was fed the commercial diet for 120 days, followed by the high-cholesterol diet for another 29 days. Group D was kept on the high-cholesterol diet for 29 days, and was subsequently fed the low-cholesterol, commercial diet for 91 days and again the high-cholesterol diet for 29 days. Group E first received for 29 days the commercial diet to which $4.5 \%$ Questran $^{\text {(8) }}$ (Mead Johnson \& Co, Evansville, IN, U.S.A.) was added; this product consists of $44.4 \%$ anhydrous cholestyramine resin and $55.6 \%$ carrier. Subsequently, the animals were fed the low-cholesterol diet for 91 days and the high-cholesterol diet for 29 days. The experimental design is illustrated in Table 1. Groups A and B are control groups for time effects. The hypothesis to be tested was that the responses of serum cholesterol to the high-cholesterol diet during the last period in groups $\mathrm{D}$ and $\mathrm{E}$ would differ from the corresponding response in group $\mathrm{C}$ because of an imprinting effect of the diets fed during the first 29 days.

All diets were in powdered form. Diets and water were provided ad libitum. Individual body weights were measured and food intake was recorded for each group.

\section{Cholesterol analyses}

Blood samples were taken in the non-fasting state by orbital puncture under light diethyl-ether anesthesia between 08.00 and $10.00 \mathrm{~h}$. Serum total cholesterol was measured enzymatically using the kit (Monotest) supplied by Boehringer Mannheim, GmbH, F.R.G. The use of serum calibrators has been described [15].

At the end of the experiment livers were removed. Extraction and analysis of cholesterol was performed exactly as described [16].

\section{Enzymes in plasma}

At the end of the experiment the activities of several enzymes in plasma were 
determined: alanine amino transferase, aspartate amino transferase, alkaline phosphatase and lactate dehydrogenase. Analyses were performed on a centrifugal analyser (Multistat III - FLS, Instrumentation Laboratory, Harrow, U.K.), according to the recommendations of the German Society of Clinical Chemistry [17]. Reagents were purchased from Boehringer Mannheim, GmbH, F.R.G.

\section{Statistics}

Student's 2-tailed $t$-test was used.

\section{Results}

\section{Growth performance}

Table 2 documents body weight, body-weight gain and feed intake of the rats. In all groups and at all stages of the experiment feeding the high-cholesterol diet caused somewhat higher mean body weights. Except for group B during the last period (days 119-149) the high-cholesterol diet invariably induced faster group-mean body weight gain. This is mosst likely related to the higher energy density of the highcholesterol diet, which contained $5 \%$ of olive oil. This also explains the lower feed intake on this diet during days 0 to 29 in groups B and D and during days $29-120$ in group $\mathbf{B}$.

\section{Serum cholesterol}

Compared with the pre-experimental value, the concentration of serum cholesterol

TABLE 2

\section{BODY WEIGHT, BODY-WEIGHT GAIN AND FEED INTAKE OF THE RATS}

Results are expressed as means \pm SD for 10 animals per group; only mean feed intakes are given because the animals were housed in groups. For experimental design, see Table 1.

\begin{tabular}{|c|c|c|c|c|c|c|c|c|c|c|}
\hline \multirow[b]{3}{*}{ Body weight (g) } & \multicolumn{10}{|c|}{ Dietary group code } \\
\hline & \multicolumn{2}{|l|}{$\bar{A}$} & \multicolumn{2}{|l|}{ B } & \multicolumn{2}{|l|}{$\mathrm{C}$} & \multicolumn{2}{|l|}{$\mathrm{D}$} & \multicolumn{2}{|l|}{$\mathrm{E}$} \\
\hline & & & & & & & & & & \\
\hline day -3 & 137 & \pm 12 & 138 & \pm 14 & 139 & \pm 12 & 138 & \pm 14 & 138 & \pm 12 \\
\hline day 28 & 175 & \pm 16 & 187 & \pm 20 & 178 & \pm 12 & 185 & \pm 13 & 178 & \pm 19 \\
\hline day 119 & 213 & \pm 21 & 232 & \pm 24 & 221 & \pm 14 & 218 & \pm 15 & 218 & \pm 25 \\
\hline day 149 & 218 & \pm 21 & 237 & \pm 24 & 232 & \pm 11 & 228 & \pm 15 & 230 & \pm 28 \\
\hline \multicolumn{11}{|c|}{ Body weight gain (g/day) } \\
\hline days -3 to 28 & \multicolumn{2}{|c|}{$1.22 \pm 0.24$} & \multicolumn{2}{|c|}{$1.55 \pm 0.30^{\mathrm{a}}$} & \multirow{2}{*}{\multicolumn{2}{|c|}{$1.25 \pm 0.25$}} & \multicolumn{2}{|c|}{$1.51 \pm 0.21^{\mathrm{a}}$} & \multicolumn{2}{|c|}{$1.27 \pm 0.29$} \\
\hline days 28 to 119 & \multirow{2}{*}{\multicolumn{2}{|c|}{$\begin{array}{l}0.42 \pm 0.09 \\
0.17 \pm 0.21\end{array}$}} & \multirow{2}{*}{\multicolumn{2}{|c|}{$\begin{array}{l}0.50 \pm 0.09 \\
0.15 \pm 0.14\end{array}$}} & \multirow{2}{*}{\multicolumn{2}{|c|}{$\begin{array}{ll}0.48 \pm & 0.05 \\
0.35 & 0.35\end{array}$}} & \multirow{2}{*}{\multicolumn{2}{|c|}{$\begin{array}{l}0.37 \pm 0.07 \\
0.33 \pm 0.15\end{array}$}} & \multirow{2}{*}{\multicolumn{2}{|c|}{$\begin{array}{ll}0.44 \pm & 0.13 \\
0.42 \pm & 0.26\end{array}$}} \\
\hline days 119 to 149 & & & & & & & & & & \\
\hline \multicolumn{11}{|l|}{ Feed intake (g/day) } \\
\hline days 0 to 29 & \multicolumn{2}{|l|}{13.4} & \multicolumn{2}{|c|}{12.7} & \multicolumn{2}{|l|}{13.6} & \multicolumn{2}{|l|}{12.9} & \multicolumn{2}{|l|}{13.9} \\
\hline days 29 to 120 & \multicolumn{2}{|l|}{13.3} & \multicolumn{2}{|c|}{12.8} & \multicolumn{2}{|l|}{13.5} & \multicolumn{2}{|l|}{13.6} & \multicolumn{2}{|l|}{13.6} \\
\hline days 120 to 149 & \multicolumn{2}{|l|}{12.2} & \multicolumn{2}{|c|}{12.4} & \multicolumn{2}{|l|}{12.1} & \multicolumn{2}{|l|}{11.9} & \multicolumn{2}{|l|}{12.2} \\
\hline
\end{tabular}

${ }^{a}$ Significantly different from groups $\mathrm{A}, \mathrm{C}$ and $\mathrm{E}(P<0.05)$. 
TABLE 3

SERUM TOTAL CHOLESTEROL CONCENTRATIONS OF THE RATS

Results are expressed as means \pm SD for 10 animals per group.,$+ n-9$. For experimental design, see Table 1.

\begin{tabular}{|c|c|c|c|c|c|}
\hline & \multicolumn{5}{|c|}{ Dietary group code } \\
\hline & $\begin{array}{l}\overline{\mathrm{A}} \\
(\mathrm{mmol} / \mathrm{I}\end{array}$ & $\begin{array}{l}\text { B } \\
(\mathrm{mmol} / \mathrm{l})\end{array}$ & $\begin{array}{l}\mathrm{C} \\
(\mathrm{mmol} / 1)\end{array}$ & $\begin{array}{l}\mathrm{D} \\
(\mathrm{mmol} / \mathrm{l})\end{array}$ & $\begin{array}{l}\mathrm{E} \\
(\mathrm{mmol} / \mathrm{l})\end{array}$ \\
\hline$\overline{\text { Day }-\overline{6}}$ & $2.43 \pm 0.19$ & $2.42 \pm 0.17$ & $2.40 \pm 0.16$ & $2.39 \pm 0.15$ & $2.38 \pm 0.16$ \\
\hline Day 8 & $2.07 \pm 0.21$ & $20.60 \pm 4.00$ & $2.08 \pm 0.19$ & $20.00 \pm 6.70$ & $2.00 \pm 0.15$ \\
\hline Day 29 & $2.07 \pm 0.20$ & $17.00 \pm 5.40$ & $1.98 \pm 0.16$ & $15.50 \pm 3.95$ & $2.23 \pm 0.28$ \\
\hline Day 80 & $2.14 \pm 0.46$ & $12.47 \pm 1.99$ & $1.94 \pm 0.27$ & $1.89 \pm 0.22$ & $1.96 \pm 0.15$ \\
\hline Day 120 & $2.18 \pm 0.29$ & $11.10 \pm 3.46$ & $2.11 \pm 0.28$ & $1.97 \pm 0.20$ & $2.11 \pm 0.24+$ \\
\hline Day 128 & $2.20 \pm 0.25$ & $12.05 \pm 2.81$ & $13.83 \pm 3.51$ & $14.62 \pm 3.76$ & $14.18 \pm 4.04$ \\
\hline Day 149 & $2.12 \pm 0.23$ & $12.63 \pm 5.38$ & $18.13 \pm 6.19$ & $17.23 \pm 5.33$ & $16.27 \pm 5.16$ \\
\hline
\end{tabular}

decreased by $13 \%$ in the rats fed the low-cholesterol diet (Table 3, groups A and C). Feeding cholestyramine (group E, days 8 and 29) did not affect serum cholesterol when compared with the low-cholesterol diet (groups A and C).

Feeding the high-cholesterol diet caused an 8-fold increase in the non-fasting serum cholesterol after 8 days (groups B and D). Similar cholesterolemic effects were seen earlier in female rats of the same strain and fed the same high-cholesterol diet, but sampled after a 24-h fast [18]. Subsequently serum cholesterol fell to a level of about $12 \mathrm{mmol} / 1$ after 80 days, and remained at this concentration (group B). When the high-cholesterol diet was replaced in group D after 29 days by the low-cholesterol diet, serum cholesterol levels declined to control values (group D, day 80).

During days 120-149 all animals except for the control group A, received the high-cholesterol diet. The final mean serum cholesterol values of groups C, D and E were significantly $(P<0.05)$ higher than in the animals fed the high-cholesterol diet during the entire experiment (group B). The difference in the cholesterolemic response to the high-cholesterol diet between groups $\mathrm{C}, \mathrm{D}$ and $\mathrm{E}$ did not reach statistical significance.

\section{Liver cholesterol}

Feeding the high-cholesterol diet induced a marked enlargement and grey-white appearance of the liver. Table 4 shows that liver wet weight was about $60 \%$ higher in rats fed the high-cholesterol diet for 29 days (groups C, D and E) than in control animals (group A). In the animals fed the high-cholesterol diet for 149 days (group B) liver wet weight was about $150 \%$ higher. Relative liver weight showed a 2 -fold increase on the high-cholesterol diet. There were no statistically significant differences in liver wet weight and relative liver weight between groups C, D and E.

Liver cholesterol, both in absolute amount and expressed relative to liver weight, was elevated by $50 \%$ in animals fed the high-cholesterol diet for 29 days (groups C, $\mathrm{D}$ and $\mathrm{E}$ ). In the animals kept on the high-cholesterol diet for 149 days (group B) the accumulation of cholesterol in liver was 50 to $150 \%$ higher than in any other group 


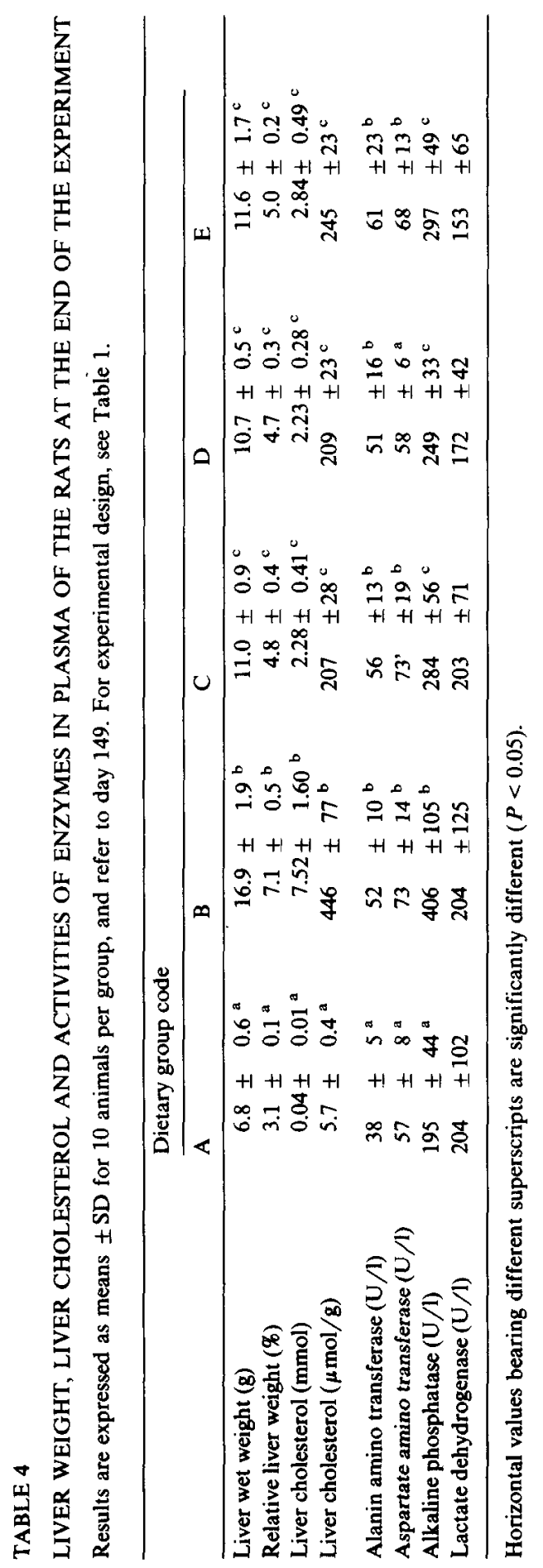


(Table 3). There were no differences in liver cholesterol between groups $\mathrm{C}, \mathrm{D}$ and $\mathrm{E}$, suggesting that the diet fed during early life has no major effect on the accumulation of cholesterol in the liver during later cholesterol feeding.

\section{Liver enzymes in plasma}

The well-known high amounts of cholesterol that are stored in rat liver after cholesterol feeding (cf. Table 4) prompted us to study liver function by the measurement of indicator enzymes in plasma. As shown in Table 4 the highcholesterol diet (groups B, C, D and E) caused on average a $30 \%$ increase in the activities of alanine amino transferase, aspartate amino transferase (except for group D) and alkaline phosphatase. The duration of cholesterol feeding only appeared to influence alkaline phosphatase; the activity of this enzyme was about 1.5 -fold increased in the animals challenged with the high-cholesterol diet during the entire experiment (group B). Cholesterol loading had no effect on the activity of lactate dehydrogenase.

\section{Discussion}

Our study addressed the question whether early dietary history affects the later response of serum and liver cholesterol to dietary challenge. Under our experimental conditions no evidence was obtained that consumption of an extremely hypercholesterolemic diet (containing $2 \%$ cholesterol and $0.5 \%$ cholate) in early life influences the later responses of serum and liver cholesterol to the same diet. Other studies with rats have shown a negative $[9,10]$, positive $[11,19]$ or no association at all [12-14] between early cholesterol or fat feeding and the subsequent response of serum cholesterol to a cholesterol-enriched diet. Experiments with baboons [20] and humans [21] also presented evidence that there are no such long-term effects.

Results obtained with cholestyramine feeding of guinea pigs suggest that cholesterol metabolism can be permanently influenced. In post-weaned [8] and neonatal [7] guinea pigs previous cholestyramine feeding reduced the cholesterolemic response to cholesterol loading during later life. Cholestyramine, a basic anion exchange resin, binds bile acids in the gut and carries them into the feces $[7,8]$ thereby causing a drain on the bile acid pool. The liver responds by converting more cholesterol into bile acids. The increased production of bile acids induced by cholestyramine in the diet of the guinea pigs persisted after the withdrawal of the drug $[7,8]$. This persistent effect may be related to the improved handling of dietary cholesterol at the later stage. In our rats, however, no such imprinting effect on the sensitivity to a high-cholesterol diet was observed. In addition, there was no effect of early intake of cholestyramine on the accumulation of cholesterol in liver after feeding the high-cholesterol diet in later life. The difference in animal species may explain the conflicting results.

Although our study does not present any evidence for imprinting effects on cholesterol metabolism, it is clear that a certain form of adaptation to high cholesterol intakes does exist. Serum cholesterol in the rats fed the high-cholesterol diet during the entire experiment (group B) showed a rapid increase to levels of about $20 \mathrm{mmol} / \mathrm{l}$ within 8 days (Table 3 ). Subsequently, serum cholesterol fell to a 
concentration of $12 \mathrm{mmol} / 1$ after about another 70 days and remained constant. This occurred despite continued consumption of the high-cholesterol diet at approximately the same daily intake (Table 2). Part of the decrease in serum cholesterol, may be due to a change in distribution of cholesterol between serum and liver. Liver cholesterol, unlike serum cholesterol, was found to increase with time on the high-cholesterol diet (Table 4). The capacity to store cholesterol in the liver is probably an important mechanism in the regulation of serum cholesterol levels, at least in non-steady state conditions [22]. At the end of the experiment the rats fed the high-cholesterol diet during the entire experiment were found to have $7520 \mu \mathrm{mol}$ of cholesterol in their liver and only $100 \mu \mathrm{mol}$ in their serum compartment (assuming that the rats contained $8 \mathrm{ml}$ of serum). Apart from the liver no significant amounts of cholesterol are stored in the carcass of rats [22].

This study suggests that in rats the feeding of a high-cholesterol diet or a diet containing cholestyramine during early life does not influence the accumulation of cholesterol in serum and liver while fed a high-cholesterol diet in later life. It is important to further study conditions possibly causing imprinting effects on atherogenesis and on cholesterol metabolism.

\section{Acknowledgements}

We thank G. Van Tintelen (Small Animal Center, CKP, Agricultural University) for taking care of the rats and G. Den Engelsman and Z. Kruyswijk (Department of Human Nutrition) for expert analytical assistance.

\section{References}

1 Kannel, W.B. and Dawber, T.R., Atherosclerosis as a pediatric problem, J. Pediat., 80 (1972) 544.

2 Breslow, J.L., Pediatric aspects of hyperlipidemia, Pediatrics, 62 (1978) 510.

3 Hodgson, P.A., Ellefson, R.D., Elveback, L.R., Harris, L.E., Nelson, R.A. and Weidman, W.H., Comparison of serum cholesterol in children fed high, moderate, or low cholesterol milk diets during neonatal period, Metabolism, 25 (1976) 739.

4 Marmot, M.G., Page, C.M., Atkins, E. and Douglas, J.W.B., Effects of breast-feeding on plasma cholesterol and weight in young adults, J. Epidemiol. Comm. Health, 34 (1980) 164.

5 Friedman, G. and Goldberg, S.J., Concurrent and subsequent serum cholesterols of breast- and formula-fed infants, Am. J. Clin. Nutr., 28 (1975) 42.

6 Huttunen, J.K., Saarinen, U.M., Kostianen, E. and Siimes, M.A., Fat composition of the infant diet does not influence subsequent serum lipid levels in man, Atherosclerosis, 46 (1983) 87.

7 Li, J.R., Bale, L.K. and Subbiah, M.T.R., Effect of enhancement of cholesterol degradation during neonatal life of guinea pigs on its subsequent response to dietary cholesterol, Atherosclerosis, 32 (1979) 93.

8 Hassan, A.S., Gallon, L.S., Yunker, B.S. and Subbiah, M.T.R., Effect of enhancement of cholesterol catabolism in guinea pigs after weaning on subsequent response to dietary cholesterol, Am. J. Clin. Nutr., 35 (1982) 546.

9 Reiser, R. and Sidelman, Z., Control of serum cholesterol homeostasis by cholesterol in the milk of the suckling rat, J. Nutr., 102 (1972) 1009.

10 Hahn, P. and Koldovsky, O., Late effect of premature weaning on blood cholesterol levels in adult rats. Nutr. Rep. Int., 13 (1976) 87.

11 Green, M.H., Dohner, E.L. and Green, J.B., Influence of dietary fat and cholesterol on milk lipids and on cholesterol metabolism in the rat, J. Nutr., 111 (1981) 276. 
12 Kris-Etherton, P.M., Layman, D.K., Vanzyl York, P. and Frantz, Jr., I.D., The influence of early nutrition on the serum cholesterol of the adult rat, J. Nutr. 109 (1979) 1244.

13 Hulbron, G., Aubert, R., Bourgeois, F. and Lemonnier, D., Early cholesterol feeding: Are there long-term effects in the rat?, J. Nutr. 112 (1982) 1296.

14 Beynen, A.C., Van Tintelen, G. and Katan, M.B., Previous high-fat or high-carbohydrate intake and the subsequent cholesterolemic response to a high-cholesterol diet in rats, Nutr. Rep. Int., 30 (1984) 545 .

15 Katan, M.B., Kromhout, D., Van der Haar, F. and Schouten, F.J.M., Standardization of serum cholesterol assays using serum calibrators and direct addition of Liebermann-Burchard reagent, Clin. Chem. 28 (1982) 683.

16 Beynen, A.C., Den Engelsman, G., Scholz, K.E. and West, C.E., Casein-induced hypercholesterolemia in rabbits - Distribution of cholesterol, triglycerides and phospholipids between serum and liver, Ann. Nutr. Metab. 27 (1983) 117.

17 Optimierte Standard-Methode der Deutschen Gesellschaft für Klinische Chemie, Z. Klin. Chem. Klin. Biochem., 10 (1972) 182.

18 Beynen, A.C., Weinans, G.J.B. and Katan, M.B., Arylesterase activities in the plasma of rats, rabbits and humans on low- and high-cholesterol diets, Comp. Biochem. Physiol., 78B (1984) 669.

19 Coates, P.M., Brown, S.A., Sonawane, B.R. and Koldovsky, O., Effect of early nutrition on serum cholesterol levels in adult rats challenged with high fat diet, J. Nutr. 113 (1983) 1046.

20 Mott, G.E., McMahan, C.A., Kelley, J.M., Mersinger Farley, C. and McGill, Jr., H.C., Influence of infant and juvenile diets on serum cholesterol, lipoprotein cholesterol, and apolipoprotein concentrations in juvenile baboons ( Papio sp.), Atherosclerosis, 45 (1982) 191.

21 McMurry, M.P., Connor, W.E. and Cerqueira, M.T., Dietary cholesterol and the plasma lipids and lipoproteins in the Tarahumara Indians - A people habituated to a low cholesterol diet after weaning, Am. J. Clin. Nutr. 35 (1982) 741.

22 Beynen, A.C., Boogaard, A., Van Laack, H.L.J.M. and Katan, M.B., Cholesterol metabolism in two strains of rats with high or low response of serum cholesterol to a cholesterol-rich diet, J. Nutr., 114 (1984) 1640. 